\title{
O NEXO CAUSAL EM SAÚDE/DOENÇA MENTAL NO TRABALHO: UMA DEMANDA PARA A PSICOLOGIA
}

\author{
Maria da Graça Jacques \\ Universidade Federal do Rio Grande do Sul, Porto Alegre, Brasil
}

\begin{abstract}
RESUMO: Estabelecer o nexo causal em saúde/doença mental no trabalho tem se apresentado como uma nova demanda à psicologia como ciência e profissão nos seus diferentes campos de atuação. Este texto examina a interlocução entre trabalho e saúde/doença mental no percurso histórico da psicologia. Apresenta, também, alguns procedimentos referentes ao diagnóstico e à justificativa de nexo causal entre trabalho e quadros psicopatológicos com base na Portaria do 1339/99 do Ministério da Saúde do Brasil. Mesmo admitindo o reducionismo que a relação causal produz em se tratando de quadros psicopatológicos, a exigência legal a impõe para o reconhecimento como doenças relacionadas com o trabalho e o acesso aos benefícios previdenciários decorrentes.
\end{abstract}

PALAVRAS-CHAVE: nexo causal; saúde do trabalhador; saúde mental.

\section{THE CAUSAL NEXUS ON MENTAL HEALTH/ILLNESS RELATED TO WORK: A NEW DEMAND FOR PSYCHOLOGY}

ABSTRACT: Establishing the causal nexus on mental health/illness related to work is a new demand for psychology as a science and as a profession in all fields of activity. This text examines the interlocution between work and mental health/illness in the course of the history of psychology. It also presents some procedures referring to the diagnosis and the justification of the causal nexus between work and psychopathological illness. Even if we consider the causal nexus as a reductionism in psychopathological illness, this is a legal requirement to be recognized as an illness related to work and to obtain social welfare agency benefits.

KEYWORDS: causal nexus, worker's health, mental health.

Em 18 de março de 1994, Zero Hora, jornal diário porto-alegrense, publica uma matéria com o título 'Empregado humilhado ficou paralítico'. A reportagem relata o caso de um metalúrgico que havia perdido a voz e o movimento das pernas após ser humilhado pela chefia. Segundo a mesma reportagem, o trabalhador, examinado por uma psicóloga do Centro de Referência em Saúde do Trabalhador local, teve o seu estado descrito como "sofrimento mental desencadeado no trabalho", parecer que o setor de perícias do Instituto Nacional de Seguro Social (INSS) levou em consideração ao incluí-lo no segurodoença.

O reconhecimento de nexo causal pelos órgãos previdenciários entre o trabalho e um transtorno psíquico não é comum, tanto que o inusitado da ocorrência mereceu espaço na mídia local. Também, a participação de uma psicóloga na elaboração do diagnóstico cujo parecer subsidiou a decisão da perícia do INSS, aponta para uma demanda que vem crescendo no âmbito da psicologia.

A discussão acerca do nexo causal voltou à cena com a edição da medida provisória de número 316 , em 11 de agosto de 2006, apresentada pelo governo federal, que prevê o nexo técnico-epidemiológico. Tal medida inverte o ônus da prova em alguns casos ao determinar o registro automático como doença relacionada ao trabalho de determinadas patologias em função de altas incidências em determinados ambientes de trabalho.
Os vínculos entre o trabalho e o adoecimento psíquico vêm ganhando visibilidade crescente. Corroboram para essa visibilidade o número elevado de casos de depressão e suicídio entre a população rural associado ao uso indiscriminado de agrotóxicos (Ministério da Saúde, 2001; Silva, Novato-Silva, Faria \& Pinheiro, 2005) e o número crescente de transtornos mentais entre trabalhadores que vivenciaram processos de reestruturação produtiva nos seus locais de trabalho (Chanlat, 1996; Fonseca, 2002; Lima, 1995; Ministério da Saúde, 2001).

Tambémé crescente o número de trabalhadores acometidos por agravos mentais. Segundo estimativas da World Health Organization ([WHO], 1985), os chamados transtornos mentais menores acometem cerca de $30 \%$ dos trabalhadores ocupados e os transtornos mentais graves, cerca de 5 a $10 \%$. No Brasil, segundo estatísticas do INSS, os transtornos mentais ocupam a $3^{\text {a }}$ posição entre as causas de concessão de benefícios previdenciários (Ministério da Saúde, 2001).

O quadro atual demanda do psicólogo, nos seus diferentes campos de atuação, re-significar a função do trabalho no processo de saúde/doença mental. Re-significar já que na história da psicologia como ciência e profissão, o trabalho ocupou, de modo geral, uma posição secundária, constituindo-se tão somente como um campo de aplicação dos conhecimentos psicológicos ou como um dos indicativos de uma vida adaptada e 'normal'. 
Este texto examina a interlocução entre trabalho e saúde/doença mental no percurso histórico da psicologia. Também, apresenta e discute alguns procedimentos, no âmbito da psicologia, referentes ao diagnóstico e ao nexo causal entre trabalho e quadros psicopatológicos, com base no Decreto n ${ }^{\circ} 3048 / 99^{1}$ (com suas posteriores alterações) (Ministério da Previdência e Assistência Social, 1999) que trata sobre a regulamentação das doenças profissionais e do trabalho e, na Portaria 1339/99² (Ministério da Saúde, 1999) que traz a lista legal de doenças relacionadas ao trabalho.

A inserção do psicólogo nas equipes de saúde pública, nos vários espaços institucionais como escolas, hospitais, organizações empresariais, sindicatos, etc. e na clínica privada requer um instrumental teórico e metodológico que lhe permita estabelecer o nexo causal entre o trabalho e o adoecimento mental em acordo com as regras da legislação brasileira. O campo da saúde do trabalhador se mostra como um campo promissor para o exercício profissional da psicologia e, ainda, não há uma adequada formação para atuar nesta área, inclusive no que se refere à determinação do nexo causal.

\section{Trabalho \& Saúde na trajetória da Psicologia}

No contexto europeu do século XIX em que a psicologia se constituiu como uma disciplina independente $o$ trabalho ocupava uma posição central como categoria de análise. São exemplos: no final do século anterior, Adam Smith publicava, em 1776, a obra 'A riqueza das Nações' em que o promovia como fonte de todas as abundâncias; em 1836, Thonsen propunha a divisão da pré-história com base nos materiais utilizados na fabricação de utensílios; Leão XIII, em 1891, publicava a primeira encíclica dedicada ao tema trabalho.

São também expressões da importância conferida ao trabalho neste período histórico as concepções de Hegel e Marx. Em Hegel (1985), o homem, mediante o trabalho, transforma o mundo ao mesmo tempo em que se transforma a si mesmo, humanizando-se. Na concepção de Marx (1983), o trabalho se apresenta como condição básica para a emancipação humana e como atividade fundamental e responsável pelo processo de hominização.

No entanto, a aproximação da psicologia com os princípios naturalistas e evolucionistas obstaculiza sua apropriação de concepções de natureza humana de caráter social. A tendência pragmática que os estudos em psicologia assumem no cenário estadounidense, aliada a forte demanda do setor industrial crescente, orienta os estudos e as práticas da psicologia do trabalho como campo de aplicação. A dicotomia entre teoria e prática corrobora para que permanecesse como tal, distanciando-se da produção de conhecimentos da psicologia enquanto ciência.
No âmbito da saúde/doença mental, os séculos XVII, XVIII e, notadamente o século XIX, assistem a consolidação do saber médico sobre a loucura com base em explicações racionais por influência da valorização crescente da razão, herança cartesiana (Foucault, 1979, 1999). Surgem os grandes alienistas (Esquirol, Pinel, entre outros) preocupados com os desvios enquanto atentados individuais à ordem moral e social. A loucura passa a sofrer uma condenação enquanto associada à ociosidade e a internação, já esboçada em outros períodos históricos, ganha uma nova forma, o hospício, como um espaço exclusivo e diferenciado de confinamento em relação aos demais desajustados sociais. As preocupações dominantes são a descrição e a classificação das doenças mentais e o tratamento moral através da hospitalização compulsória dos seus portadores.

No final do século XIX, início do século XX, com a criação e consolidação da psicanálise, as relações objetais, em especial as da primeira infância, ganham relevância na etiologia dos transtornos mentais. A posição de destaque que ocupou a psicanálise no campo conceitual da psicologia clínica, imprópria para dar conta das relações de trabalho, é apontada por Dejours (1988) como responsável pelo pouco desenvolvimento da psicopatologia do trabalho. Habermas (1982) faz crítica semelhante, referindose ao desprezo da visão psicanalítica para as questões referentes ao trabalho.

Na obra freudiana são poucas as referências a categoria trabalho. Elas aparecem em 'A psicologia das Massas', texto de 1921 (Freud, 1967, v. 1), e na compreensão das relações de força entre os instintos e o ego, em 'Análise terminável e interminável' (Freud, 1967, v. 3). Este último texto, em que o trabalho é citado como um possível fator inespecifíco e secundário na etiologia do transtorno psíquico, coincide com a produção do filme de Charles Chaplin, 'Tempos Modernos' (1936) em que o cineasta expressa de modo explícito a relação entre o trabalho, organizado segundo o modelo taylorista-fordista, e o distúrbio mental.

Com relação ao modelo taylorista-fordista e suas implicações no funcionamento psíquico dos trabalhadores, o próprio Henry Ford (s/d) manifestava preocupação com problemas decorrentes das rotinas de trabalho demandadas pelos processos de trabalho. A identificação das linhas de montagem fordistas como fontes de sofrimento psíquico dos operários é também tema do primeiro número do Journal of Mental Higyene, de 1917.

A implantação do modelo taylorista-fordista em larga escala contribuiu para dar visibilidade aos efeitos do trabalho sobre o psiquismo dos trabalhadores. No entanto, há registros anteriores que expressam preocupações semelhantes: Ramazzini, em 1700, apontou o sofrimento mental dos escriturários e tipógrafos como uma das explicações 
para a ocorrência de lesões osteomusculares nessas categorias profissionais (Ramazzini, 2000); Marx e Engels (1989), em meados do século XIX, alertaram sobre as possíveis conseqüências do trabalho no "sistema nervoso" dos trabalhadores.

No âmbito da psicologia, o modelo taylorista-fordista representou a aproximação definitiva da psicologia com o mundo do trabalho, buscando a aplicação dos conhecimentos e das técnicas psicológicas às relações de trabalho. Tal aproximação se fez a partir de estudos a respeito da fadiga sob o enfoque do aumento da produtividade. A publicação, em 1913, do livro de Hugo Münsterberg, marca formalmente a criação da chamada psicologia industrial.

Nos espaços laborais a psicologia se consolida com o objetivo de medir as diferenças individuais na busca do 'homem certo para o lugar certo' com o propósito de aumentar o rendimento dos trabalhadores. Desenvolve métodos e técnicas psicológicas de seleção de pessoal aplicadas, posteriormente, à avaliação de desempenho e ao treinamento.

No entanto, são os estudos de Elton Mayo, realizados na empresa Western Electric, em Hawthorne, Chicago, entre 1924 e 1934, que marcam o reconhecimento dos fatores psicológicos como decisivos para o aumento da produtividade dos trabalhadores. Deriva-se desse movimento, reconhecido como Movimento das Relações Humanas, a aplicação dos estudos sobre motivações, satisfação no trabalho, clima e cultura organizacionais e uma prática psicológica aplicada aos variados contextos empresariais (não só às indústrias e como psicologia do trabalho).

As diferentes escolas no campo da administração de pessoal recorrem aos conhecimentos e às técnicas psicológicas para sustentar seus princípios e implantar suas ações. Consolida-se a noção de organização, enquanto entidade ontológica, como objeto da psicologia, renominandoa de psicologia organizacional.

Reconhece-se, no exame da trajetória da psicologia como área de aplicação, enquanto psicologia industrial, psicologia do trabalho e psicologia organizacional, uma prioridade às questões referentes à gestão de pessoal e uma tendência hegemônica para a utilização de métodos e técnicas psicológicas com o objetivo de classificação e adaptação dos trabalhadores, com base em normas compatíveis com a acumulação ampliada do capital. As questões relacionadas à saúde/doença mental não fazem parte do cotidiano de trabalho do psicólogo. É ilustrativa a análise de Spink (1996) sobre os experimentos de Hawthorne, em especial, a retirada de duas operárias do estudo por reivindicarem melhores condições salariais e alguns privilégios, por serem classificadas como neuróticas e passíveis de serem tratadas pela psiquiatria.

A aplicação da psicologia ao mundo do trabalho recebe as primeiras críticas a partir da segunda metade do século
XX. Fromm (1956, p. 269) alertava sobre as formas de emprego do conhecimento psicológico que "incrementam o empresário de utilidades sem comprometer-se com a situação do trabalhador."

O ano de 1956 registra, também, a publicação do artigo 'A neurose das telefonistas' por Le Guillant et al. (apud Lima, 2006a), considerado um marco importante no desenvolvimento dos estudos no campo da saúde/ doença mental em seus vínculos com o trabalho. Le Guillant é representante do movimento da psiquiatria francesa, movimento responsável por empregar pela primeira vez, por Sivadon, em 1952, a expressão psicopatologia do trabalho (apud Lima, 2002).

A principal preocupação de Sivadon estava voltada para o caráter terapêutico do trabalho (ergoterapia) em pacientes acometidos pelos mais diversos distúrbios mentais. É através da ergoterapia que a categoria trabalho se cruza, de modo mais preciso, com a trajetória dos estudos e intervenções sobre doença mental. Nesta mesma linha, Le Guillant, a partir da constatação sobre o número significativo de empregadas domésticas nos hospícios franceses, desenvolve suas pesquisas com o objetivo de demonstrar a existência de uma relação entre o contexto laboral e a frequiência e a gravidade dos distúrbios mentais apresentados pelos trabalhadores.

Na vertente da psicologia clínica o trabalho ocupa uma posição secundária. Erikson (1972), a respeito, registra que era comum as informações sobre o trabalho sequer serem apresentadas pelos clínicos nos estudos de casos. Tavares (2004) atribui a dificuldade de integrar as visões da psicologia aplicada à clínica e ao trabalho à dicotomia estabelecida por uma visão parcial que, ou externaliza a fonte dos problemas, ou a coloca no sujeito, em sua história ou estrutura.

Concepções teóricas que não dão conta da multiplicidade e complexidade da constituição do humano e do seu psiquismo, perspectivas reducionistas na compreensão do processo saúde/doença mental e a fragmentação do campo psicológico são algumas das explicações para a relativa invisibilidade dos vínculos entre trabalho e saúde mental no campo conceitual da psicologia. A hegemonia da psicologia aplicada nos espaços de trabalho, seus princípios e arcabouço teórico contribuem para esta invisibilidade.

O movimento de crítica a este modelo hegemônico, em que no Brasil são representativos os trabalhos de Codo (1985), Jacques (1989), Spink (1996), entre outros, e, a aproximação com o campo conceitual da psicologia social fundamentada no materialismo histórico estimula e alicercia a aproximação da psicologia à área de saúde do trabalhador. As observações de Codo (2006) sintetizam algumas dessas críticas: “... psicologia industrial organizacional que insiste em inventar um ser humano desprovido de afetos, ou, como na Teoria das Relações Humanas, 
em instrumentalizar o afeto como forma de aumentar a produtividade" (p. 26).

Também contribui para esta aproximação a superação dos modelos hegemônicos das práticas de intervenção e regulação das relações entre saúde e trabalho agrupados como medicina do trabalho, engenharia e segurança e saúde ocupacional. Segundo Nardi (1997) o movimento de tendência mundial que emerge no campo da saúde do trabalhador passa a propor uma perspectiva interdisciplinar que abre espaço para a contribuição de outros campos disciplinares como o da psicologia.

\section{O nexo causal entre saúde/doença mental e trabalho}

A inserção da psicologia no campo da saúde do trabalhador the abre um conjunto variado de possibilidades de atuação, entre essas, o estabelecimento do nexo causal entre o trabalho e o adoecimento mental. $\mathrm{O}$ reconhecimento deste vínculo permeia os diferentes campos de atuação da psicologia e implica uma compreensão do humano que dá conta de suas várias dimensões. Conforme Codo (2006, p. 186):

O trabalho é o modo de ser do homem, e como tal permeia todos os niveis de sua atividade, seus afetos, sua consciência, o que permite que os sintomas se escondam em todos os lugares: quem garante que o chute no cachorro ao retornar para casa não se deve a razões de ordem profissional?

A Portaria 1339/99 (Ministério da Saúde, 1999) apresenta os princípios norteadores utilizados no Brasil para o diagnóstico das doenças relacionadas ao trabalho e tem um capítulo dedicado aos chamados "transtornos mentais e do comportamento relacionados ao trabalho". Segundo o Manual do Ministério da Saúde (2001) que toma como referência tal portaria e o Decreto 3048/99 (Ministério da Previdência e Assistência Social, 1999) com suas alterações, o estabelecimento do nexo causal entre a doença e a atividade atual ou pregressa do trabalhador representa o ponto de partida para o diagnóstico e a terapêutica corretos, para as ações de vigilância e para o registro das informações.

Os fatores que contribuem para o perfil de adoecimento dos trabalhadores são: doenças comuns sem qualquer relação com o trabalho, doenças comuns modificadas no aumento da freqüência ou na precocidade de manifestação em decorrência do trabalho, doenças comuns nas quais se somam ou se multiplicam condições provocadoras ou desencadeadoras em decorrência do trabalho e os agravos específicos tipificados pelos acidentes de trabalho e doenças profissionais. Os três últimos fatores constituem o que se convencionou nomear como doenças relacionadas ao trabalho (Mendes \& Dias, 1999).
As doenças relacionadas ao trabalho se distribuem entre os grupos I, II e III, segundo a classificação de Schilling, adotada no Brasil. No primeiro grupo, em que o trabalho aparece como causa necessária, estariam as doenças legalmente reconhecidas. No grupo II, o trabalho aparece como fator contributivo mas não necessário e, no grupo III, o trabalho é considerado um provocador de um distúrbio latente ou agravador de doença já estabelecida (Ministério da Saúde, 2001). Nos grupos II e III estão aquelas doenças não definidas a-priori como resultantes do trabalho, mas que podem ser causadas por este. Nesses casos impõese a necessidade de laudo técnico que estabeleça os nexos causais.

Os transtornos mentais e do comportamento, conforme nomenclatura do Ministério da Saúde (2001), estão, em geral, classificados nos grupos II ou III, exceto aquelas causadas por substâncias tóxicas ou por fatores bem específicos como traumas físicos, por exemplo. Incluem-se neste caso (grupo I), quando excluídas causas não ocupacionais: demência, delirium, transtorno cognitivo leve, transtorno mental orgânico, episódios depressivos em trabalhadores expostos a substâncias químicas neurotóxicas e síndrome de fadiga relacionada ao trabalho. Também são classificados no grupo I: o estado de estresse póstraumático e o transtorno do ciclo vigília-sono devido a fatores não orgânicos em trabalhadores que exercem suas atividades em turnos alternados e/ou trabalho noturno.

Ainda fazem parte da lista de transtornos mentais e do comportamento relacionados ao trabalho segundo a Portaria MS 1339/99: o alcoolismo crônico relacionado ao trabalho, o grupo classificado como outros transtornos neuróticos e a síndrome de burn-out ou síndrome do esgotamento profissional (classificados ou nos grupo II ou no grupo III). Evidências epidemiológicas de excesso de prevalência em determinados grupos ocupacionais justificam a classificação no grupo II. Episódios depressivos e síndrome de fadiga relacionada ao trabalho quando não associadas à exposição a algumas substâncias químicas podem ser classificadas nos grupos II ou III (Ministério da Saúde, 1999).

Portanto, a contribuição do trabalho para a alteração da saúde mental se dá a partir de uma gama de aspectos, desde fatores pontuais como a exposição a agentes tóxicos até a complexa articulação de fatores relativos à organização do trabalho. No entanto, no território da saúde/ doença mental, a distribuição na classificação de Schilling se complexifica. As teorias divergem sobre o papel do trabalho no processo de adoecimento mental, considerandoo ou como determinante ou como fator desencadeante a partir de uma estrutura pré-existente. Além disso, os transtornos mentais têm uma etiologia multicausal em que conjuntos de diversos fatores interagem de modo complexo. 
Jacques, M.G. "O nexo causal em saúde/doença mental no trabalho: uma demanda para a Psicologia"

\begin{tabular}{|l|l|}
\hline $\begin{array}{l}\text { Grupo I } \\
\text { Exposição a agentes tóxicos/ } \\
\text { fatores específicos }\end{array}$ & $\begin{array}{l}\text { Demência, delirium, transtorno cognitivo leve, } \\
\text { transtorno mental orgânico, episódios depressivos, } \\
\text { síndrome de fadiga relacionada ao trabalho, estado } \\
\text { de estresse pós-traumático e transtorno do ciclo } \\
\text { vigília-sono. }\end{array}$ \\
\hline $\begin{array}{l}\text { Grupo II } \\
\text { Estudos epidemiológicos } \\
\text { demonstrando maior freqüência, } \\
\text { intensidade ou precocidade }\end{array}$ & $\begin{array}{l}\text { Alcoolismo crônico, outros transtornos neuróticos, } \\
\text { síndrome de burn-out, episódios depressivos e } \\
\text { síndrome de fadiga relacionada ao trabalho. }\end{array}$ \\
\hline $\begin{array}{l}\text { Grupo III } \\
\text { Trabalho como fator desencadeante } \\
\text { ou agravante }\end{array}$ & $\begin{array}{l}\text { Alcoolismo crônico, outros transtornos neuróticos, } \\
\text { síndrome de burn-out, episódios depressivos e } \\
\text { síndrome de fadiga relacionada ao trabalho. }\end{array}$ \\
\hline
\end{tabular}

Quadro 1. Síntese. ${ }^{3}$

Codo (2006), mesmo considerando as dificuldades para estabelecer o nexo causal, argumenta que, quer considerando o trabalho como fator desencadeante, quer considerando-o como uma das causas de um conjunto complexo de determinantes, há argumentos jurídicos, como o princípio da concausalidade, que fundamentam esse nexo. Para exemplificar, cita o caso das cardiopatias em que a jurisprudência considera como relacionada ao trabalho quando seu agravamento ou eclosão se deu devido a condições deste.

Os estudos epidemiológicos, inclusive os realizados no Brasil pelo Laboratório de Psicologia do Trabalho da Universidade de Brasília, fornecem fundamentos de relevância para justificar o nexo causal, em especial, para justificar a inclusão no grupo II. É o caso da síndrome de burn-out em educadores, resultado de pesquisa realizada com 52.000 professores das redes estaduais de vários estados do Brasil (Codo, 1999). Ainda, dentro de uma abordagem epidemiológica, cabe citar a pesquisa realizada por Lima (2004) em instituições psiquiátricas de Barbacena. Nessa pesquisa a autora apresenta análises probabilísticas de transtornos mentais pelo abuso de álcool em determinadas categorias profissionais, entre outras análises estatisticamente significativas entre trabalho e internação psiquiátrica.

$\mathrm{O}$ estabelecimento do nexo causal entre trabalho e distúrbio mental impõe a necessidade de uma investigação diagnóstica em que a anamnese ocupacional é o instrumento decisivo. Reafirma-se a célebre frase do pioneiro Ramazzini há mais de três séculos que apregoava a necessidade, na cabeceira da cama de qualquer paciente, perguntar-lhe onde trabalhava para saber se na fonte de seu sustento não se encontrava a causa de sua enfermidade.

\section{A investigação diagnóstica}

As primeiras incursões da psicologia nas questões referentes aos acidentes e doenças ocupacionais buscavam, através de métodos e técnicas psicológicas, definir o perfil do trabalhador propenso a esses eventos (Sato, 2003). Tais incursões remontam à década de 20 do século passado e reproduzem o lugar que a psicologia ocupava nos contextos laborais e sua adesão ideológica. A noção de propensão, segundo a autora supra citada, ainda se mantém no imaginário social e se expressa através de explicações individualizantes que culpabilizam o trabalhador pelo acidente ou pelo adoecimento.

A proposta atual de investigação diagnóstica no campo da saúde do trabalhador tem um outro enfoque e se constituiu como tentativas de compreender as relações entre condições de vida e de trabalho e o surgimento, a freqüência ou a gravidade dos distúrbios mentais. Segundo Lima (2006b), a investigação diagnóstica compreende: a busca de evidências epidemiológicas que revele a incidência de alguns quadros em determinadas categorias profissionais ou grupo de trabalhadores, o resgate da história de vida de cada trabalhador e as razões que apontam para o seu adoecimento, o estudo do trabalho real, a identificação dos mediadores que permitem compreender concretamente como se dá a passagem entre a experiência vivida e o adoecimento e uma complementação com informações decorrentes de exames médicos e psicológicos.

Jardim e Glina (2000) sugerem investigar na anamnese ocupacional:

1. O trabalho: os relacionamentos (incluindo os externos ao trabalho), o conhecimento e o controle que o trabalhador dispõe sobre o processo de trabalho, a natureza e o conteúdo das tarefas, o reconhecimento social que o trabalho lhe concede e a descrição detalhada das atividades realizadas.

2. As condições de trabalho: temperatura, vibração, umidade, exposição a substâncias químicas e biológicas, ruído, ventilação, equipamentos, etc. (investigação de 
importância para detectar possíveis exposições a agentes tóxicos).

3. A organização do trabalho: horário, turno, escalas, pausas, horas-extras, ritmo, políticas de pessoal, tipo de vínculo, intensidade e quantidade de trabalho (a organização de trabalho é responsável principalmente pelas repercussões na saúde psíquica dos trabalhadores).

As autoras propõem, ainda:

4. Identificar as exigências físicas (esforços, movimentos repetitivos, postura), mentais (atenção, memória, quantidade de informações a processar) e psicoafetivas (relacionamentos, vínculos).

5. Levantar as percepções dos trabalhadores sobre os riscos.

6. Localizar os momentos em que o trabalhador começa a perceber as mudanças e os problemas associados a essas mudanças.

7. Informar-se sobre condições de vida (família, moradia), uso de drogas, doenças pré-existentes.

8. Considerar a história clínica e a história do trabalho em relação à história de vida.

9. Levantar a avaliação do trabalhador sobre sua trajetória profissional e as repercussões sobre a sua saúde.

As diversas dimensões a serem investigadas através da anamnese ocupacional requerem uma ou mais entrevistas com o próprio trabalhador e com familiares, chefias e colegas de trabalho sempre que houver disponibilidade. A investigação diagnóstica pode incluir, também, a avaliação psicológica com o uso ou não de testes psicológicos.

A avaliação psicológica pode ainda ser empregada com o objetivo de identificar alterações intelectuais, sensoriais, de memória e aprendizagem, espaciais e de personalidade (alterações de comportamento e de humor) decorrentes da exposição a agentes tóxicos. A grande dificuldade ao seu uso é a inexistência de parâmetros comparativos que permitam quantificar e ou qualificar tais alterações (sendo necessário o emprego de indicadores secundários como a vida escolar, por exemplo). Uma outra dificuldade deriva do desconhecimento dos efeitos de certas substâncias o que dificulta a seleção de instrumentos e das funções psíquicas a serem avaliadas.

Os diferentes enfoques metodológicos concedem uma maior ou menor importância a cada um dos pólos da relação saúde/doença mental e trabalho. A experiência subjetiva do trabalhador é privilegiada nos enfoques que se fundamentam na psicodinâmica do trabalho; autores clássicos no estudo dessa relação como Ramazzini (2000) e Le Guillant (apud Lima, 2006a) recomendam levar em consideração fatores derivados da observação detalhada do trabalho e da vivência do trabalhador, tendência pre- sente em autores contemporâneos como, por exemplo, Clot (2006) e, no Brasil, Codo (2006) e Lima (2004).

\section{À guisa de conclusões}

Estabelecer o nexo causal entre saúde/doença mental e trabalho contribui para um diagnóstico e para uma prescrição terapêutica corretos e vem se mostrando particularmente útil quando se tratam de sintomas e sinais derivados da exposição a agentes tóxicos. Não é incomum casos de internação psiquiátrica em que a origem do problema determinante da internação não é avaliado quanto a sua possível relação com o contexto de trabalho, o que pode determinar um encaminhamento sem resolutividade.

Também, a investigação do nexo causal com o trabalho propicia ao trabalhador garantias previstas pela legislação, tanto de caráter econômico como sua estabilidade por um ano quando do retorno ao trabalho. Em alguns casos tem contribuído para diminuir a responsabilização do trabalhador pelo acidente ou pelo adoecimento e as conseqüências daí derivadas associadas à culpa imputada por outros ou a própria auto-culpabilização.

No entanto, os princípios que fundamentam o estabelecimento do nexo causal ainda se reportam a um modelo em que a ênfase recai na patologia. Sobre esse modelo Vasques-Menezes (2004) refere que a doença se sobrepõe ao paciente e este se apresenta como a-histórico em termos de sua inserção no mundo. A necessidade de enquadramento da queixa em uma classificação psicopatológica constituída em termos de sintomas e sinais acaba por encobrir o sujeito e seu sofrimento, alienando-o do seu processo de adoecimento.

Também, a ênfase na classificação psicodiagnóstica acaba por encobrir a unidade de análise enquanto relação trabalhador/contexto de trabalho, ou seja, não apenas o trabalhador ou apenas o contexto de trabalho isoladamente tomados (Sato, 2003). Para Vasques-Menezes (2004) é necessário atentar para fatores objetivos em termos de signos e sinais mas, também, para a relação do sujeito com seu trabalho e, por conseguinte, com sua vida como um todo.

No mesmo sentido, Lima (2004) ao comentar os méritos de Le Guillant ressalta a sua habilidade em compreender a forma pelo qual os determinantes sociais e individuais se articulam na gênese das doenças, superando a dicotomia entre subjetividade e objetividade, entre singular e coletivo. Ou seja: a explicação não se encontra em dados subjetivos ou derivados do contexto laboral, mas nas formas pelos quais eles se articulam, construindo uma trama complexa que se traduz na trajetória de cada trabalhador o que explica porque nem todos expostos a situações semelhantes adoecem ou manifestam o mesmo grau de desgaste. 
A relação de causalidade, mesmo que multicausal, que fundamenta o estabelecimento do vínculo entre saúde/ doença mental e trabalho, não dá conta das relações de determinação das manifestações humanas. Ainda, acaba por reduzir o conceito de saúde mental a ausência de transtornos psíquicos, deixando de levar em conta as diversas dimensões subjetivas da relação do homem com o seu trabalho.

Mesmo considerando a consolidação do nexo epidemiológico e os limites que a elaboração do nexo causal impõe, é importante que, como princípio, seja incorporado ao exercício profissional da psicologia pelas possibilidades que descortina. Possibilidades que vão além de uma psicologia aplicada ao mundo do trabalho e que redirecionam o diagnóstico e a intervenção psicológica nos diferentes campos de atuação da psicologia.

\section{Notas}

www.trt02.gov.br

www.saude.gov.br

A descrição dos quadros clínicos pode ser encontrada no Manual das doenças relacionadas ao trabalho, editado pelo Ministério da Saúde (2001)

\section{Referências}

Chanlat, J. (1996). Modos de gestão, saúde e segurança no trabalho. In E. Davel \& J. Vasconcelos (Eds.), "Recursos” humanos e subjetividade (pp. 208-229). Petrópolis, RJ: Vozes.

Clot, Y. (2006). A função psicológica do trabalho. Petrópolis, RJ: Vozes.

Codo, W. (1985). O papel do psicólogo na organização industrial (notas sobre o "lobo" mau em psicologia). In S. Lane \& W. Codo (Eds.), Psicologia social: O homem em movimento (3. ed., pp. 195-202). São Paulo, SP: Brasiliense.

Codo, W. (1999). Educação: Carinho e trabalho. Petrópolis, RJ: Vozes.

Codo, W. (2006). Por uma psicologia do trabalho: Ensaios recolhidos. São Paulo, SP: Casa do Psicólogo.

Dejours, C. (1988). A loucura do trabalho: Estudo de psicopatologia do trabalho (3. ed.). São Paulo, SP: Cortez-Oboré.

Empregado humilhado ficou paralítico. (1994, 18 mar.). Zero Hora.

Erikson, E. (1972). Identidade; juventude e crise. Rio de Janeiro, RJ: Jorge Zahar.

Fonseca, T. M. (2002). Modos de trabalhar, modos de subjetivar em tempos de reestruturação produtiva. In T. M. Fonseca(Ed.), Modos de trabalhar, modos de subjetivar (pp. 13-27). Porto Alegre, RS: Editora da Universidade Federal do Rio Grande do Sul.

Ford, H. (s/d). Minha vida e minha obra. Rio de Janeiro, RJ: BertrandBrasil.

Foucault, M. (1979). Microfísica do poder. Rio de Janeiro, RJ: Graal. Foucault, M. (1999). História da loucura. São Paulo, SP: Perspectiva. Freud, S. (1967). Obras completas (Vols. 1, 3). Madrid, España: Biblioteca Nueva.

Fromm, E. (1956). Psicoanálisis de la sociedad contemporánea. México: Fondo de Cultura Economica.
Habermas, J. (1982). Conhecimento e interesse. Rio de Janeiro, RJ: Jorge Zahar.

Hegel, G. (1985). Fenomenologia del espíritu. México: Fondo de Cultura Economica.

Jacques, M. G. (1989). O contexto histórico como produtor e produto do conhecimento: A trajetória da psicologia do trabalho. Psicologia: Reflexão e Crítica, 4(1/2), 64-70.

Jardim, S., \& Glina, D. (2000). Os diagnósticos dos transtornos mentais relacionados ao trabalho. In D. Glina \& L. Rocha (Eds.), Saúde mental no trabalho: Desafios e soluções (pp. 17-52). São Paulo, SP: VK.

Lima, M. E. (1995). Os equívocos da excelência: As novas formas de sedução na empresa. Petrópolis, RJ: Vozes.

Lima, M. E. (2002). Esboço de uma crítica à especulação no campo da saúde mental e trabalho. In M. G. Jacques \& W. Codo (Eds.), Saúde mental \& trabalho: Leituras (pp. 50-81). Petrópolis, RJ: Vozes.

Lima, M. E. (2004). A relação entre distúrbio mental e trabalho: evidências epidemiológicas recentes. In W. Codo (Ed.), O trabalho enlouquece? (pp. 139-160). Petrópolis, RJ: Vozes.

Lima, M. E. (2006a). Escritos de Louis Le Guillant: Da ergoterapia à psicopatologia do trabalho. Petrópolis, RJ: Vozes.

Lima, M. E. (2006b). Os problemas de saúde na categoria bancária: Considerações acerca do estabelecimento do nexo causal. Boletim da Saúde, 20(1), 57-68.

Marx, K. (1983). Manuscritos económico-filosóficos. In E. Fromm (Ed.), Conceito marxista de homem (8. ed., pp. 89-170). Rio de Janeiro, RJ: Zahar.

Marx, K., \& Engels, F. (1989). O capital (13. ed.). São Paulo, SP: Bertrand-Brasil.

Mendes, R., \& Dias, E. (1999). Saúde dos trabalhadores. In M. Z. Rouquayrol \& N. Almeida Filho (Eds.), Epidemiologia e saúde (3. ed., pp.431-456). Rio de Janeiro, RJ: Medsi.

Ministério da Previdência e Assistência Social. Decreto n ${ }^{\circ} 3.048$, de 06 de maio de 1999. Diário Oficial [da] União, 7 maio 1999. Retirado de http://www010.dataprev.gov.br/sislex/paginas/23/ 1999/3048.htm

Ministério da Saúde. (1999). Portaria Federal no 1.339/GM - MS, de 18 de novembro de 1999. Brasília, DF: Autor. Retirado de http:// www.saude.ba.gov.br/concurso_vigilancia/Leis\%20e\%20Portarias/ Portaria\%20Federal\%201339\%20de\%2018.11.99.pdf

Ministério da Saúde. (2001). Doenças relacionadas ao trabalho: Manual de procedimentos para os serviços de saúde. Brasília, DF: MS.

Nardi, H. (1997). Saúde do trabalhador. In A Cattani (Ed.), Trabalho e tecnologia: Dicionário crítico (pp. 219-224). Petrópolis, RJ: Vozes.

Ramazzini, B. (2000). As doenças dos trabalhadores (3. ed.). São Paulo, SP: Fundacentro.

Sato, L. (2003). Subjetividade, saúde mental e trabalho. In R. Ruiz (Ed.), Um mundo sem LER é possível (pp. 62-76). Montevidéu, Uruguai: Rel-Uita.

Silva, J. M., Novato-Silva, E., Faria, H., \& Pinheiro, T. M. (2005). Agrotóxico e trabalho: Uma combinação perigosa para a saúde do trabalhador rural. Ciência \& saúde coletiva, 10(4), 891-904.

Spink, P. (1996). Organização como fenômeno psicossocial: Notas para uma redefinição da psicologia do trabalho. Psicologia \& Sociedade, 8(1), 174-192.

Tavares, M. (2004). A clínica da confluência da história pessoal e profissional. In W. Codo (Ed.), O trabalho enlouquece? (pp. 53-104). Petrópolis, RJ: Vozes. 
Vasques-Menezes, I. (2004). Por onde passa a categoria trabalho na prática terapêutica? In W. Codo (Ed.), O trabalho enlouquece? (pp. 23-52). Petrópolis, RJ: Vozes.

World Health Organization. (1985). Expert committee on identification and control of work related diseases. Geneva, Suíça: Author.

Maria da Graça Jacques é Professora do Curso de Especialização em Medicina Social, Ergonomia e Psicologia Social e Institucional da Universidade Federal do Rio Grande do Sul (UFRGS). Endereço para correspondência: São Manoel, 2022, apto. 703, Porto Alegre, RS, 90620-110.

fjacques@terra.com.br

O nexo causal em saúde/doença mental no trabalho: uma demanda para a Psicologia

Maria da Graça Jacques

Recebido: 27/11/2006

Aceite final: 06/03/2007 